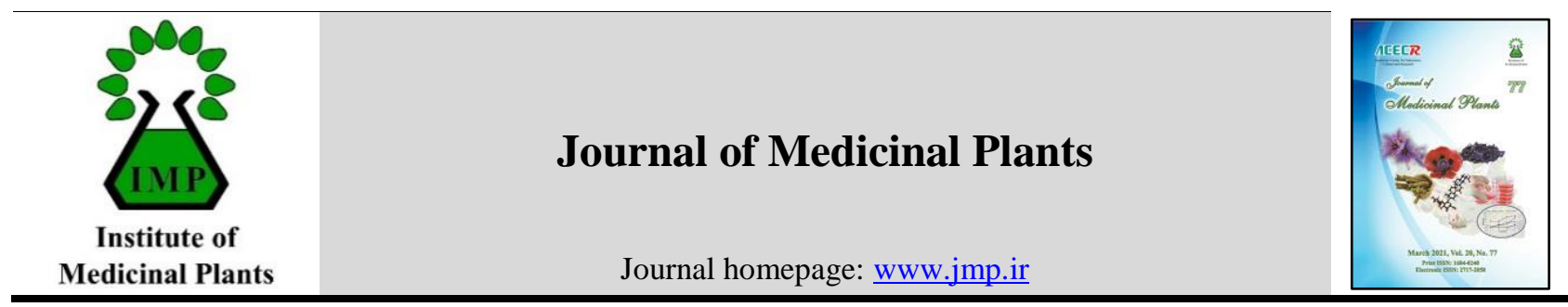

Research Article

\title{
Essential oil bioactivity evaluation of the different populations of Cupressus against adult rice weevil (Sitophilus oryzae $\mathbf{L}$.)
}

\author{
Mohammadreza Labbafi ${ }^{1}$, Maryam Ahvazi ${ }^{1}$, Farahnaz Khalighi-Sigaroodi ${ }^{1}$, Hamideh Khalaj ${ }^{2}$, \\ Soolmaz Ahmadian ${ }^{2}$, Fateme Tajabadi ${ }^{1}$, Mousa Khani ${ }^{1}$, Shahla Amini ${ }^{1, *}$ \\ ${ }^{1}$ Medicinal Plants Research Center, Institute of Medicinal Plants, ACECR, Karaj, Iran \\ ${ }^{2}$ Department of Agriculture, Payame Noor University, Tehran, Iran
}

\begin{tabular}{|c|c|}
\hline ARTICLE INFO & ABSTRACT \\
\hline $\begin{array}{l}\text { Keywords: } \\
\text { Toxicity } \\
\text { Repellency } \\
\text { Nutritional indices } \\
\text { Essential oils } \\
\text { Storage pests }\end{array}$ & $\begin{array}{l}\text { Background: A significant amount of crop production is destroyed annually by pests in } \\
\text { the storage and significant damage is caused to crops. Recently, the use of essential oils } \\
\text { as an alternative to pesticides in pest control has been considered. Due to the presence } \\
\text { of } \alpha \text {-pinene, Cupressus genus is a significant source of plant insecticides that can act as } \\
\text { fumigant, repellency and inhibitory insecticides. Objective: The aim of this study was } \\
\text { to investigate the insecticidal properties, repellency and nutritional parameters of } \\
\text { essential oils of Cupressus species on Sitophilus oryzae in } 2018 \text {. Methods: The } \\
\text { experiment was conducted in a factorial arrangement based on completely randomized } \\
\text { design with } 4 \text { replications. The essential oils of the different species and populations of } \\
\text { Cupressus were prepared by the Clevenger apparatus using a water distillation method. } \\
\text { The major constituents in the essential oils were analyzed by GC-MS and the biological } \\
\text { effects of the essential oils against adult } S \text {. oryzae were investigated. Results: In the } \\
\text { analysis of chemical compounds, } \alpha \text {-pinene was identified as the main essential oils of } \\
\text { the above species. The result showed that among the species, C. arizonica showed the } \\
\text { highest Fumigant toxicity to } S \text {. oryzae with LC } 50=172.30 \mu \text { l/L air. In investigating the } \\
\text { effect of repellency on } S \text {. oryzae, essential oils of } C \text {. sempervirens L. var. horizontalis } \\
\text { (France) with } 80.61 \% \text { showed the highest distance. Conclusion: Due to the toxicity and } \\
\text { high repellency effect of Cupressus essential oils on S. oryzae, this genus has high } \\
\text { potential for use in storage pest control. }\end{array}$ \\
\hline
\end{tabular}

\section{Introduction}

Every year, a significant amount of agricultural production in developing countries is destroyed by storage pests and crops suffer great damage [1]. Sitophilus oryzae belongs to
Coleoptera and they are storage pest, while feeding on storage materials and causes irreparable damage to crops [2]. In order to maintain the quantity and quality of stored cereals, it is necessary to reduce the population

Abbreviations: RGR, Relative Growth Rate; RCR, Relative Consumption Rate; ECI, Efficiency of Conversion of Ingested food

* Corresponding author: amini@imp.ac.ir

doi: $10.29252 / \mathrm{jmp} .20 .77 .79$

Received 11 February 2020; Received in revised form 11 November 2020; Accepted 11 November 2020

(C) 2020. Open access. This article is distributed under the terms of the Creative Commons Attribution-NonCommercial 4.0 International License (https://creativecommons.org/licenses/by-nc/4.0/) 
of storeroom insects. Considering the economic importance of pests and the problems associated with the use of fumigant chemical insecticides and the prohibition on their use [3], the substitution of other suitable methods seems necessary [4]. Essential oils and plant extracts are suitable alternatives for synthetic pesticides that have the lowest risk to humans and the environment. Essential oils extracted from plants are usually decomposed fast in nature, so they are less toxic to humans and other mammals and have less detrimental effects on the environment [5]. Cupressus is a significant source of plant insecticides. Some studies have been proven the insecticidal and fungicidal properties of the genus of Cupressus. The Cupressaceae family includes 32 genera in the world which two species of them, Cupressus arizonica and Cupressus sempervirens, exist in Iran [6]. Cupressus sempervirens L. has two varieties called Cupressus sempervirens L. var. horizontalis (Mill.) Gord (Persian name: Zarbin), and Cupressus sempervirens L. var. stricta Aiton (Persian name: Sarv-e-Shirazi) [7].

In a review article, the researchers examined the effects of plant essential oils on storage pests and listed the most important ones [8]. In one experiment, researchers examined the biological activity of acetone, ethanol extracts of Cupressus sempervirens on third instar larvae of Culex pipiens. It was found that ethanol extract is more toxic than acetone and ethanol extract. It also causes morphological abnormalities in both stages of mosquito life (larvae and adult insects) [9]. The effect of the essential oils of Cupressus sempervirens on 10 pathogenic fungi examined and showed that Cupressus sempervirens had the fungicides property [10]. In another study, the effects of the fumigant toxicity of Pinus eldarica and Cupressus sempervirens was tested on adult moths. The results showed that Cupressus sempervirens had less toxic effect on flour moth [11].

The aim of this study was to evaluate the efficacy of Cupressus species essential oils. Another aim was to investigate the insecticidal properties, repellency and nutritional parameters of Cupressus essential oils in Iran and compare it with pure essential oils prepared from France for the management of adult rice weevil.

\section{Materials and Methods}

\subsection{Plant collection and extraction of essential oils}

The aerial parts of $C$. sempervirens var. horizontalis and $C$. arizonica were collected from Tehran province and $C$. sempervirens var. horizontalis and $C$. sempervirens var. stricta were collected from Mazandaran province (Chalus valley) (Table 1 \& Fig. 1). After collection, the plants were dried in the shade. The essential oils were extracted from $100 \mathrm{~g}$ of every herbal samples for 3 hours using Clevenger apparatus. The essential oils were dehydrated with anhydrous sodium sulfate and stored in dark glass in the refrigerator $\left(3-5{ }^{\circ} \mathrm{C}\right)$ before experiments.

\subsection{Insect rearing}

Colonies of rice weevil were obtained from Agricultural Entomology Research Department of Iranian Research Institute of Plant Protection (Tehran-Iran). Colonies were reared on $300 \mathrm{~g}$ of rice and $200 \mathrm{~g}$ of flour in 1-L cans in a germinator at $27 \pm 1{ }^{\circ} \mathrm{C}$ with relative humidity $70 \pm 5 \%$ and 12:12 hours light-dark photoperiod. The released insects were fed on rice and flour for 3 weeks and then removed. After 7-14 days since the first insects emerged on rice and flour, they were used as the same-age insects for testing [12]. 
Table 1. Location, latitude, longitude and altitude of studied Cupressus species

\begin{tabular}{ccccccc}
\hline Species & Persian Name & $\begin{array}{c}\text { Herbarium } \\
\text { code }\end{array}$ & Location & $\begin{array}{c}\text { Latitude } \\
(\mathbf{N})\end{array}$ & $\begin{array}{c}\text { Longitude } \\
(\mathbf{E})\end{array}$ & $\begin{array}{c}\text { Altitude } \\
(\mathbf{m})\end{array}$ \\
\hline $\begin{array}{c}\text { C. sempervirens L. var. } \\
\text { horizontalis } \text { (Mill.) Gord }\end{array}$ & Zarbin & $1388(\mathrm{MPIH})$ & Tehran & $35^{\circ} 45^{\prime} 11^{\prime \prime}$ & $51^{\circ} 1678^{\prime \prime}$ & 1450 \\
\hline $\begin{array}{c}\text { C. sempervirens } \text { L. var. } \\
\text { horizontalis } \text { (Mill.) Gord }\end{array}$ & Zarbin & $1387(\mathrm{MPIH})$ & Chalus & $36^{\circ} 31^{\prime} 95^{\prime \prime}$ & $51^{\circ} 20^{\prime} 79^{\prime \prime}$ & 319 \\
\hline $\begin{array}{c}\text { C. sempervirens } \text { L. var. } \\
\text { stricta } \text { Aiton }\end{array}$ & Sarv-e-Shirazi & $1386(\mathrm{MPIH})$ & Chalus & $36^{\circ} 31^{\prime} 95^{\prime \prime}$ & $51^{\circ} 20^{\prime} 79^{\prime \prime}$ & 319 \\
\hline C. arizonica Greene & $\begin{array}{c}\text { Sarv-e-Simin, } \\
\text { Sarv-e-Noghrei }\end{array}$ & $1389(\mathrm{MPIH})$ & Tehran & $35^{\circ} 77^{\prime} 06^{\prime \prime}$ & $51^{\circ} 41^{\prime} 60^{\prime \prime}$ & 1460 \\
\hline
\end{tabular}

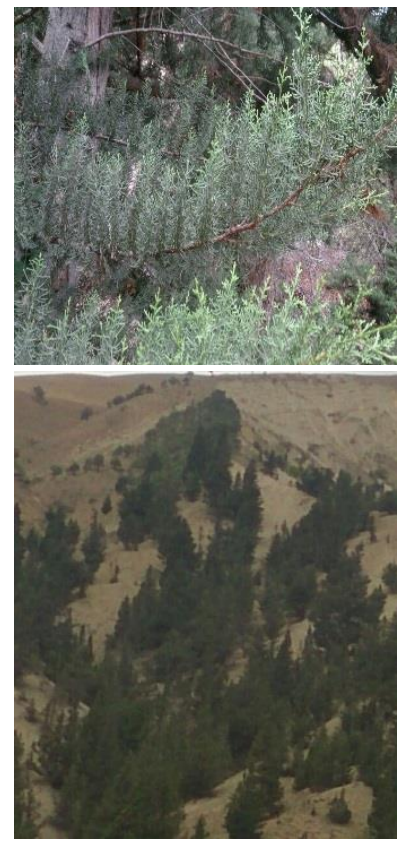

C. sempervirens var. horizontalis

(Zarbin: Chalus)

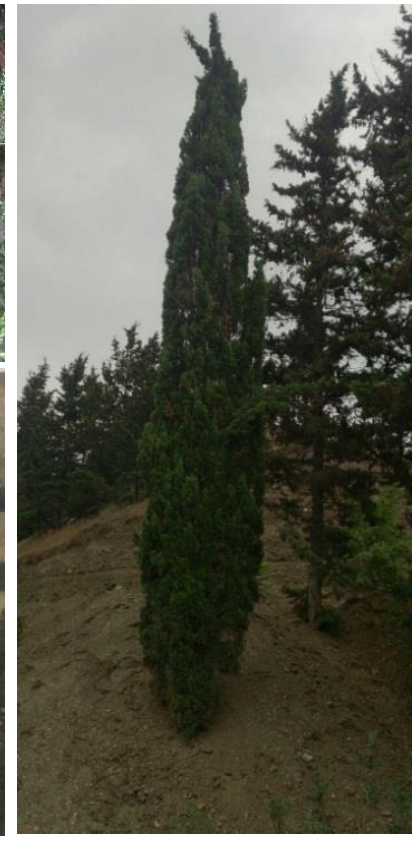

C. sempervirens var. stricta

(Sarv-e-Shirazi: Chalus)

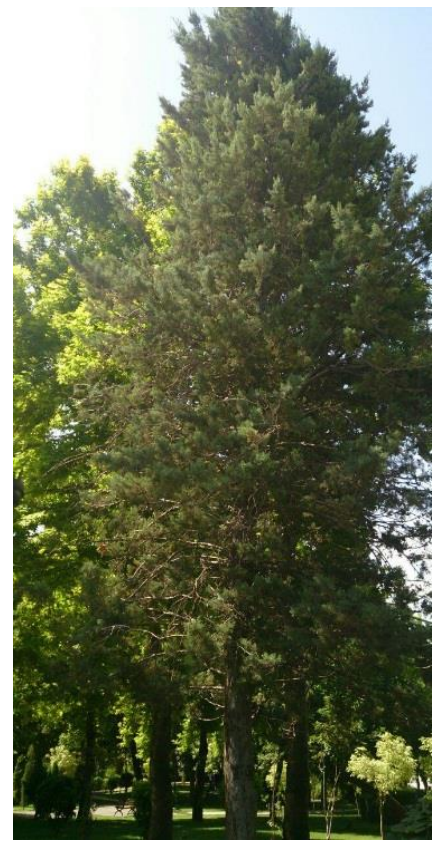

C. arizonica

(Sarv-e-Simin: Tehran)

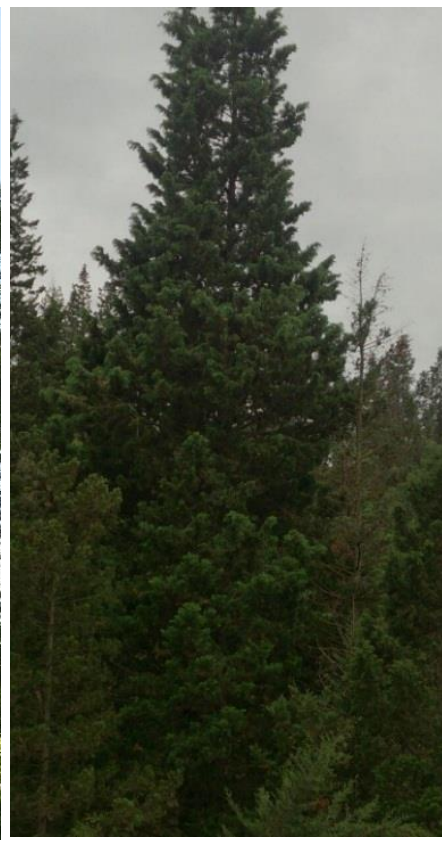

C. sempervirens var. horizontalis

(Zarbin: Tehran)

Fig. 1. Figure of studied Cupressus species

\subsection{Fumigant toxicity of essential oils}

Fumigant toxicity measurements of essential oils were performed according to the method of Amini, et al. [12]. 15 adult rice weevil (7-14 days old) were transferred on $5 \mathrm{~g}$ of rice in 70-ml glass containers, then a filter paper with $2 \mathrm{~cm}$ in diameter inoculated with essential oils (with concentrations calculated in the $0,71.5,143,214$, $286,357,428.5 \mu \mathrm{l} / \mathrm{L}$ of air) was inserted into the glass container lid. The control treatment was included 15 adult rice weevil on $5 \mathrm{~g}$ of rice in glass containers but filter paper did not inoculate with essential oils.

In this experiment, insects that were unable to move their legs were considered to be dead. The experiment was carried out in a completely randomized design with factorial arrangement with 4 replications in Ecophysiology Laboratory, 
Medicinal Plants Research Center, Institute of Medicinal Plants, ACECR in 2018. The essential oils of 5 samples including $C$. sempervirens var. horizontalis (Tehran \& Chalus), C. sempervirens var. stricta (Chalus), C. arizonica (Tehran) and C. sempervirens (France) was performed on rice lice. Mortality rates were counted after 24, 48 and 72 hours since the experiment was started and $\mathrm{LC}_{50}$ was determined using Polo Plus software [13].

\subsection{Repellency of the essential oils}

The effect of repellency of prepared essential oils was performed on a filter paper by environmental method [14]. For this purpose, filter paper $(9 \mathrm{~cm})$ is divided into two halves with essential oils at concentrations of $10,15,20,25 \mu \mathrm{l}$ per $31.79 \mathrm{~cm}^{2}$ and the other half was just stained with solvent (acetone) as a control. After 10 minutes of treatment and complete evaporation of acetone, two pieces of filter paper were bonded by adhesive tape and placed together in the bottom of the petri dishes. Then, fifteen adult insects (7-14 day old) were placed in the center of the filter paper. The number of insects in each of the two sections after 1,2, 3, 4 and 5 hours were counted and the percentage of repellency was calculated according to following formula [15]:

$$
\mathrm{PR}=\left[\left(\mathrm{N}_{\mathrm{c}}-\mathrm{N}_{\mathrm{t}}\right) /\left(\mathrm{N}_{\mathrm{c}}+\mathrm{N}_{\mathrm{t}}\right)\right] \times 100
$$

$\mathrm{N}_{\mathrm{c}}$ : the number of insects on the untreated surface $\mathrm{N}_{\mathrm{t}}$ : the number of insects on the treated surface

\subsection{Evaluation of nutritional indicators}

In order to evaluate nutritional indices, the feeding rate of adult rice weevil from floured discs was evaluated. Flour disks were prepared according to the method of Xie et al. [16] with modifications made by Huang et al. [17]. To make flour disks into petri dishes $9 \mathrm{~cm}$, a mixture of $0.2 \mathrm{~g}$ flour and $1 \mathrm{~mL}$ of water was poured to make the resulting paste into a disc. Petri dishes were then placed in a germinator at $27 \pm 1{ }^{\circ} \mathrm{C}$ and $70 \pm 5 \%$ relative humidity for 48 hours to dry the discs. Afterward, discs were weighed with 0.0001 sensitive scale and doses of 0.2, 0.4, 0.8 and $1.5 \mu \mathrm{l}$ of prepared essential oils in $150 \mu \mathrm{l}$ acetone were added to each disc. Only $150 \mu 1$ acetone was used in the control samples. In each replicate before the start of the experiment, fifteen adult insects that had been starved for 24 hours were weighed with a precision scale of 0.0001. They were added to Petri dishes containing the disc and fed for three days in the germinator with above mentioned conditions. Three days after feeding, the amount of food eaten, live insects weight and flour discs in petri dishes were weighted again and the three investigated indicators were calculated using the following formulas:

1) Relative Growth Rate $(\mathrm{RGR})=(\mathrm{A}-\mathrm{B}) /(\mathrm{B} \times$ day $)$ A: Live insect weight after three days ( $\mathrm{mg} /$ insect) B: Initial weight of insect ( $\mathrm{mg} /$ insect)

2) Relative Consumption Rate $(R C R)=D /(B \times$ day $)$

$\mathrm{D}$ : The amount of food eaten after three days (mg of food eaten/ insect)

3) Efficiency of Conversion of Ingested food $(\mathrm{ECI})(\%)=(\mathrm{RGR} / \mathrm{RCR}) \times 100$

The experiment was carried out as a factorial experiment in completely randomized design with different concentrations $(0.2,0.4,0.8,1.5$ $\mu \mathrm{l} / 30 \mu \mathrm{l})$ of essential oils of five plant species mentioned on rice lice with four replications.

\subsection{Analysis and identification of the essential oils}

The selected essential oils were analyzed by Agilent 6890 chromatography with $30 \mathrm{~m}$ column, $0.25 \mathrm{~mm}$ inner diameter and $0.25 \mathrm{~mm}$ thickness of BPX 5. To identify the constituents of the essential oils, the sample diluted by $\mathrm{N}$-hexane was injected to a $1 \mu \mathrm{L}$ gas chromatograph-mass spectrometer. In this experiment, ChemStation 
software was used and spectra were identified by their retention index and compared to those in reference books and articles using mass spectra of standard compounds and information contained in a computer library [18, 19].

\subsection{Data analysis}

Data of repellency test and nutritional indices were analyzed using procedures of SAS based on a completely randomized design. The normality of the transformed and untransformed data and also normality of residuals after analysis of variance were checked using stem-leaf and normal probability plots. Homoscedasticity was checked by observing graphical distribution plots of variance by mean (PROC PLOT). A general linear model for analysis of variance (PROC GLM) was used to compare treatments. Comparisons among treatments were made using the Tukey test where analysis of variance showed significant differences among means. In all experiments, differences between treatments were considered significant at $\mathrm{P}<0.05$ and mean values are given as the mean \pm SD.

\section{Results}

\subsection{Chemical composition analysis}

The identified compounds in the essential oils of the studied plants are shown in Table 2. The analyzed showed that $\alpha$-pinene and $\delta$-2-carene were the two major components in all examined Cupressus species.

\subsection{Yields of the essential oils}

The yields of the essential oils were 2.25, 2.7, 0.74 and $1.30 \% \mathrm{w} / \mathrm{v}$ for $C$. sempervirens var. horizontalis (Tehran), C. sempervirens var. horizontalis (Chalus), C. sempervirens var. stricta (Chalus) and C. arizonica (Tehran), respectively.

\subsection{Fumigant toxicity of essential oils}

The results showed that with increasing concentration and exposure time, the mortality rate in $S$. oryzae increases. Mortality percentages in $C$. sempervirens (France), C. sempervirens var. stricta, and $C$. arizonica after 48 hours in 286 and $428.5 \mu \mathrm{l} / \mathrm{L}$ air dose were $90-98 \%$ and $100 \%$, respectively. The lowest percentage of mortality belonged to $C$. sempervirens (Tehran), which causes $31 \%$ mortality at $286 \mu \mathrm{L} / \mathrm{L}$ air and $63 \%$ mortality at $357 \mu \mathrm{L} / \mathrm{L}$ air after 48 hours on S. oryzae (Table 3).

\subsection{Medium lethal concentration $\left(L_{50}\right)$ of the essential oils}

$\mathrm{LC}_{50}$ values of the essential oils on adult $S$. oryzae showed that $C$. sempervirens (Tehran) $(525.6 \mu \mathrm{l} / \mathrm{L}$ air $)$ and $C$. arizonica $(172.30 \mu \mathrm{1} / \mathrm{L}$ air $)$ had the most and lowest $\mathrm{LC}_{50}$, respectively (Table 4).

Table 2. Chemical composition of examined Cupressus species

\begin{tabular}{cccccccc}
\hline No. & Compounds & KI & $\begin{array}{c}\text { C. sempervirens } \\
\text { var. horizontalis } \\
\text { (France) }\end{array}$ & $\begin{array}{c}\text { C. sempervirens } \\
\text { var. horizontalis } \\
\text { (Tehran) }\end{array}$ & $\begin{array}{c}\text { C. sempervirens } \\
\text { var. horizontalis } \\
\text { (Chalus) }\end{array}$ & $\begin{array}{c}\text { C. sempervirens } \\
\text { var. stricta } \\
\text { (Chalus) }\end{array}$ & $\begin{array}{c}\text { C. } \\
\text { arizonica } \\
\text { (Tehran) }\end{array}$ \\
\hline 1 & $\begin{array}{c}\text { Santolina } \\
\text { triene }\end{array}$ & 906 & - & 0.08 & - & - & - \\
2 & Tricyclene & 925 & 0.32 & 0.15 & 0.18 & - & - \\
3 & $\alpha$-Thujene & 929 & 0.64 & 0.15 & 0.24 & - & 0.84 \\
4 & $\alpha$-Pinene & 940 & $\mathbf{5 4 . 9 8}$ & $\mathbf{3 4 . 4 3}$ & $\mathbf{4 0 . 2 8}$ & - & $\mathbf{4 5 . 4 8}$ \\
5 & Camphene & 952 & - & - & 0.16 & 1.15 & - \\
6 & Camphene & 953 & 1.18 & - & & - & 0.28 \\
\hline
\end{tabular}


Table 2. Chemical composition of examined Cupressus species (Continued)

\begin{tabular}{|c|c|c|c|c|c|c|c|}
\hline No. & Compounds & KI & $\begin{array}{c}\text { C. sempervirens } \\
\text { var. horizontalis } \\
\text { (France) }\end{array}$ & $\begin{array}{c}\text { C. sempervirens } \\
\text { var. horizontalis } \\
\text { (Tehran) }\end{array}$ & $\begin{array}{c}\text { C. sempervirens } \\
\text { var. horizontalis } \\
\text { (Chalus) }\end{array}$ & $\begin{array}{c}\text { C. sempervirens } \\
\text { var. stricta } \\
\text { (Chalus) }\end{array}$ & $\begin{array}{c}C . \\
\text { arizonica } \\
\text { (Tehran) }\end{array}$ \\
\hline 7 & $\begin{array}{c}\text { Thuja-2,4(10)- } \\
\text { diene }\end{array}$ & 959 & 0.23 & - & - & - & - \\
\hline 8 & Sabinene & 978 & 0.95 & 0.74 & 0.79 & 0.38 & 5.6 \\
\hline 9 & $\beta$-Pinene & 983 & 1.31 & 0.95 & 1.22 & 1.67 & 2.11 \\
\hline 10 & Myrcene & 995 & 1.36 & 2.02 & 1.9 & 1.92 & 5.76 \\
\hline 11 & $\delta$-2-Carene & 1015 & 14.03 & 23.56 & 18.27 & 22.55 & 0.51 \\
\hline 12 & $\alpha$-Terpinene & 1023 & 0.2 & 0.09 & 0.13 & - & 0.65 \\
\hline 13 & para-Cymene & 1026 & - & 0.06 & - & - & - \\
\hline 14 & Sylvestrene & 1029 & - & 0.22 & 0.16 & 0.19 & - \\
\hline 15 & $o$-Cymene & 1032 & - & 0.07 & - & - & - \\
\hline 16 & $p$-Cymene & 1033 & 0.95 & - & - & - & 0.69 \\
\hline 17 & Limonene & 1036 & 2.11 & 1.02 & 1.08 & 1.14 & 9.87 \\
\hline 18 & $\beta$-Phellandrene & 1038 & 0.28 & - & 0.45 & 0.43 & 2.28 \\
\hline 19 & $E$ - $\beta$-Ocimene & 1051 & - & 0.06 & - & - & 0.16 \\
\hline 20 & $\gamma$-Terpinene & 1065 & 0.41 & 0.19 & 0.25 & - & 1.02 \\
\hline 21 & Isoterpinolene & 1086 & - & - & - & 0.2 & - \\
\hline 22 & Terpinolene & 1092 & 1.4 & 3.12 & 2.76 & 2.88 & 0.93 \\
\hline 23 & $p$-Cymenene & 1101 & 0.42 & - & - & - & - \\
\hline 24 & Linalool & 1109 & 0.21 & 0.2 & - & - & - \\
\hline 25 & $\begin{array}{c}\text { trans- } \\
\text { Pinocarveol }\end{array}$ & 1153 & 0.36 & - & - & - & - \\
\hline 26 & Camphor & 1160 & - & - & - & - & 0.29 \\
\hline 27 & Karahanaenone & 1167 & - & 0.49 & - & - & - \\
\hline 28 & Umbellulone & 1183 & - & - & - & - & 5.3 \\
\hline 29 & $\begin{array}{l}\text { para-Mentha- } \\
\text { 1,5-dien-8-ol }\end{array}$ & 1184 & - & 0.09 & - & - & - \\
\hline 30 & Terpinene-4-ol & 1193 & 0.84 & 0.4 & 0.47 & - & 2.31 \\
\hline 31 & $\alpha$-Terpineol & 1210 & 0.56 & - & - & - & 0.61 \\
\hline 32 & $\gamma$-Terpineol & 1207 & - & 0.15 & - & - & - \\
\hline 33 & Citronellol & 1236 & - & - & - & - & 0.82 \\
\hline 34 & $\begin{array}{c}\text { Thymol, methyl } \\
\text { ether }\end{array}$ & 1238 & - & - & - & - & 0.51 \\
\hline 35 & $\begin{array}{l}\text { Carvacrol, } \\
\text { methyl ether }\end{array}$ & 1247 & 1.05 & - & 0.12 & - & 0.21 \\
\hline 36 & Dec-9-en-1-ol & 1266 & - & - & - & - & 0.15 \\
\hline 37 & Bornyl acetate & 1294 & 0.27 & - & 0.19 & - & - \\
\hline 38 & Isobornyl acetate & 1292 & - & 0.09 & - & - & - \\
\hline 39 & $\begin{array}{c}\text { neo-Dihydro } \\
\text { carveol acetate }\end{array}$ & 1302 & - & 0.79 & - & - & - \\
\hline 40 & 3-Thujyl acetate & 1303 & 0.38 & - & - & - & 0.42 \\
\hline 41 & $\begin{array}{l}\text { cis-Piperitol } \\
\text { acetate }\end{array}$ & 1341 & - & - & 0.72 & 0.7 & - \\
\hline
\end{tabular}


Table 2. Chemical composition of examined Cupressus species (Continued)

\begin{tabular}{|c|c|c|c|c|c|c|c|}
\hline No. & Compounds & $\mathbf{K I}$ & $\begin{array}{c}\text { C. sempervirens } \\
\text { var. horizontalis } \\
\text { (France) }\end{array}$ & $\begin{array}{c}\text { C. sempervirens } \\
\text { var. horizontalis } \\
\text { (Tehran) }\end{array}$ & $\begin{array}{c}\text { C. sempervirens } \\
\text { var. horizontalis } \\
\text { (Chalus) }\end{array}$ & $\begin{array}{c}\text { C. sempervirens } \\
\text { var. stricta } \\
\text { (Chalus) }\end{array}$ & $\begin{array}{c}C . \\
\text { arizonica } \\
\text { (Tehran) }\end{array}$ \\
\hline 42 & $\alpha$-Cubebene & 0.84 & 0.84 & 0.89 & - & 0.35 & 0.4 \\
\hline 43 & $\alpha$-Terpinyl acetate & 2.23 & 2.23 & 4.98 & 2.93 & 2.74 & - \\
\hline 44 & $\alpha$-Copaene & 0.35 & 0.35 & 0.2 & 0.24 & - & - \\
\hline 45 & $\beta$-Bourbonene & 1390 & - & - & 0.09 & - & - \\
\hline 46 & $\beta$-Cubebene & 1393 & - & 0.11 & - & - & - \\
\hline 47 & Longifolene & 1421 & 0.34 & - & 0.17 & - & 0.27 \\
\hline 48 & $\beta$-Cedrene & 1424 & - & 1.13 & - & - & - \\
\hline 49 & $\beta$-Funebrene & 1425 & - & - & 1.7 & 0.41 & - \\
\hline 50 & $\alpha$-Cedrene & 1427 & 1.67 & - & - & - & - \\
\hline 51 & E-Caryophyllene & 1429 & 0.73 & 0.7 & 0.53 & 1.5 & 0.5 \\
\hline 52 & $\beta$-Cedrene & 1436 & 0.46 & - & 0.47 & - & - \\
\hline 53 & $\beta$-Gurjunene & 1438 & - & 0.09 & - & - & - \\
\hline 54 & cis-Muurola-3,5-diene & 1454 & - & - & 0.15 & - & 2.93 \\
\hline 55 & $\alpha$-Humulene & 1467 & 0.62 & 0.66 & 0.5 & 1.43 & - \\
\hline 56 & cis-Muurola-4(14),5-diene & 1471 & - & - & 0.51 & - & - \\
\hline 57 & $\begin{array}{c}\text { epi- } \\
\text { Bicyclosesquiphellandrene }\end{array}$ & 1472 & - & 1.89 & - & - & 5.29 \\
\hline 58 & $\alpha$-Amorphene & 1484 & 1.15 & 0.63 & 0.77 & 0.67 & - \\
\hline 59 & Germacrene D & 1492 & 0.68 & 7.21 & 6.25 & 8.59 & - \\
\hline 60 & $\gamma$-Amorphene & 1502 & - & 0.35 & - & - & - \\
\hline 61 & Epizonarene & 1505 & - & 0.77 & - & 0.29 & 2.12 \\
\hline 62 & $\alpha$-Muurolene & 1507 & 0.75 & 0.32 & 0.43 & 0.25 & - \\
\hline 63 & $\gamma$-Cadinene & 1511 & 0.55 & 0.13 & 0.41 & 0.33 & - \\
\hline 64 & 7-epi- $\alpha$-Salinene & 1523 & - & 0.34 & - & - & - \\
\hline 65 & $\delta$-Cadinene & 1527 & 1.43 & 1.19 & 1.25 & 1.04 & 0.58 \\
\hline 66 & trans-Calamenene & 1532 & 0.53 & 0.33 & - & - & 0.98 \\
\hline 67 & $E$-Nerolidol & 1568 & - & - & - & - & 0.57 \\
\hline 68 & Cedrol & 1628 & - & 2.9 & - & - & - \\
\hline 69 & epi-Cedrol & 1631 & 1.62 & - & 9.37 & 1.26 & 0.48 \\
\hline 70 & $\alpha$-Cadinol & 1672 & - & 0.16 & 0.15 & - & - \\
\hline 71 & $\begin{array}{c}\text { 11-nor-Cadin-5-en-4-one, } \\
\text { isomer B }\end{array}$ & 1706 & - & - & - & - & 0.54 \\
\hline 72 & Manoyl oxide & 2006 & - & - & 0.22 & 0.3 & - \\
\hline 73 & Isopimaradiene & 2009 & - & - & - & 0.75 & - \\
\hline \multirow[t]{2}{*}{74} & Sandaracopimarinal & 2206 & - & - & 0.36 & - & - \\
\hline & Total & - & 98.39 & 94.1 & 95.87 & 98.6 & 97.4 \\
\hline
\end{tabular}

$\mathrm{KI}=$ Kovats index; Percentage $>5 \%$ are shown in bold 
Essential oil bioactivity ...

MR. Labbafi, et al

Table 3. Mean mortality percentage of rice weevil at different exposure times and concentrations from 5 essential oils compared to control

\begin{tabular}{|c|c|c|c|}
\hline \multirow{2}{*}{ Species } & \multirow{2}{*}{$\begin{array}{c}\text { Concentration } \\
(\mu \mathrm{L} / \mathrm{L} \text { air })\end{array}$} & \multicolumn{2}{|c|}{ Mortality percentage (Exposure time) } \\
\hline & & 24 (hour) & 48 (hour) \\
\hline \multirow{6}{*}{$\begin{array}{c}\text { C. sempervirens var. } \\
\text { horizontalis } \\
\text { (Tehran) }\end{array}$} & 71.5 & 0 & 0 \\
\hline & 143 & 0 & 0 \\
\hline & 214 & 0 & 0 \\
\hline & 286 & 7 & 31 \\
\hline & 357 & 33 & 63 \\
\hline & 428.5 & 33 & 80 \\
\hline \multirow{6}{*}{$\begin{array}{l}\text { C. sempervirens var. } \\
\text { horizontalis } \\
\text { (Chalus) }\end{array}$} & 71.5 & 0 & 0 \\
\hline & 143 & 5 & 31 \\
\hline & 214 & 11 & 65 \\
\hline & 286 & 40 & 80 \\
\hline & 357 & 46 & 91 \\
\hline & 428.5 & 49 & 100 \\
\hline \multirow{6}{*}{$\begin{array}{c}\text { C. sempervirens var. } \\
\text { stricta } \\
\text { (Chalus) }\end{array}$} & 71.5 & 0 & 0 \\
\hline & 143 & 0 & 0 \\
\hline & 214 & 14 & 41 \\
\hline & 286 & 52 & 92 \\
\hline & 357 & 66 & 98 \\
\hline & 428.5 & 93 & 100 \\
\hline \multirow{6}{*}{$\begin{array}{l}\text { C. arizonica } \\
\text { (Tehran) }\end{array}$} & 71.5 & 23 & 35 \\
\hline & 143 & 49 & 69 \\
\hline & 214 & 62 & 85 \\
\hline & 286 & 76 & 97 \\
\hline & 357 & 88 & 100 \\
\hline & 428.5 & 100 & 100 \\
\hline \multirow{6}{*}{$\begin{array}{c}\text { C. sempervirens } \\
\text { (France) }\end{array}$} & 71.5 & 1 & 4 \\
\hline & 143 & 26 & 51 \\
\hline & 214 & 35 & 72 \\
\hline & 286 & 50 & 90 \\
\hline & 357 & 71 & 93 \\
\hline & 428.5 & 95 & 100 \\
\hline
\end{tabular}

Table 4. $\mathrm{LC}_{50}$ values the essential oils for 5 species on $S$. oryzae insects after $72 \mathrm{~h}$

\begin{tabular}{lcccc}
\hline \multicolumn{1}{c}{ Species } & df & $\mathbf{X}^{\mathbf{2}}$ & Heterogeneity & $\begin{array}{c}\text { LC } \mathbf{5 0}(\mathbf{C I}) \\
(\boldsymbol{\mu l} / \mathbf{L} \text { air })\end{array}$ \\
\hline C. sempervirens var. horizontalis (Tehran) & 4 & 0.545 & 0.136 & $525.666(474.6-713.05)$ \\
C. sempervirens var. horizontalis (Chalus) & 4 & 3.120 & 0.780 & $491.829(451.75-567.08)$ \\
C. sempervirens var. stricta (Chalus) & 4 & 6.37 & 1.59 & $411.099(358.51-661.31)$ \\
C. arizonica (Tehran) & 4 & 18.710 & 4.677 & $172.360(142.2-143.22)$ \\
C. sempervirens (France) & 4 & 9.77 & 2.44 & $255.069(225.27-300.46)$ \\
\hline
\end{tabular}

$\mathrm{LC}_{50}$ : Medium lethal concentration; df: degree of freedom; CI: Confidence interval
3.5. The repellency effect of the essential oils
concentration, the repellency effect increased. It
Comparison of the repellency effect of the can also be concluded that these essential oils essential oils showed that with increasing have a significant difference, according to Fig. 2 
and standard bars. In general, the results showed that the essential oils of $C$. sempervirens (France) had the highest repellency effect $(80.61 \%)$ and even at low concentrations $\left(10 \mu 1 / 31.79 \mathrm{~cm}^{2}\right)$ it has the highest repellency effect than other essential oils. The essential oils of $C$. sempervirens var stricta and $C$. arizonica (15.24 \% and $19.8 \%$ ) had the lowest repellency effect compared to other essential oils (Fig. 2).

\subsection{Evaluation of nutritional indices of the essential oils}

The RGR of $S$. oryzae showed that the effect of different essential oils and different concentration was significant at $1 \%$ and the interaction between essential oils and doses was significant at $5 \%$. The lowest relative growth rate $(0.66 \mathrm{mg} / \mathrm{mg} / \mathrm{day})$ of $S$. oryzae (Table 5 and
6) was observed in the $1.5 \mu \mathrm{l} / 30 \mu \mathrm{l}$ concentration of C. sempervirens var. horizontalis (Tehran).

Analysis of variance of RCR for S. oryzae showed that the essential oils effects was significant (1\%). All of essential oils significantly reduced RCR index Except, $C$. sempervirens (Chalus) essential oils (Table 5).

The results of the ECI showed that the essential oils and different concentration were significant at $1 \%$ level. However, C. sempervirens (France) and C. Sempervirens var. horizontalis (Chalus) showed the highest ECI in the S. oryzae with $94.30 \%$ and $94.69 \%$, respectively the essential oils of $C$. sempervirens (Tehran) with $93.12 \%$ (Table 5) caused the lowest ECI in the $S$. oryzae. The $0 \mu \mathrm{l} / 30 \mu \mathrm{l}$ concentration of the essential oils also had the lowest ECI (Table 6).

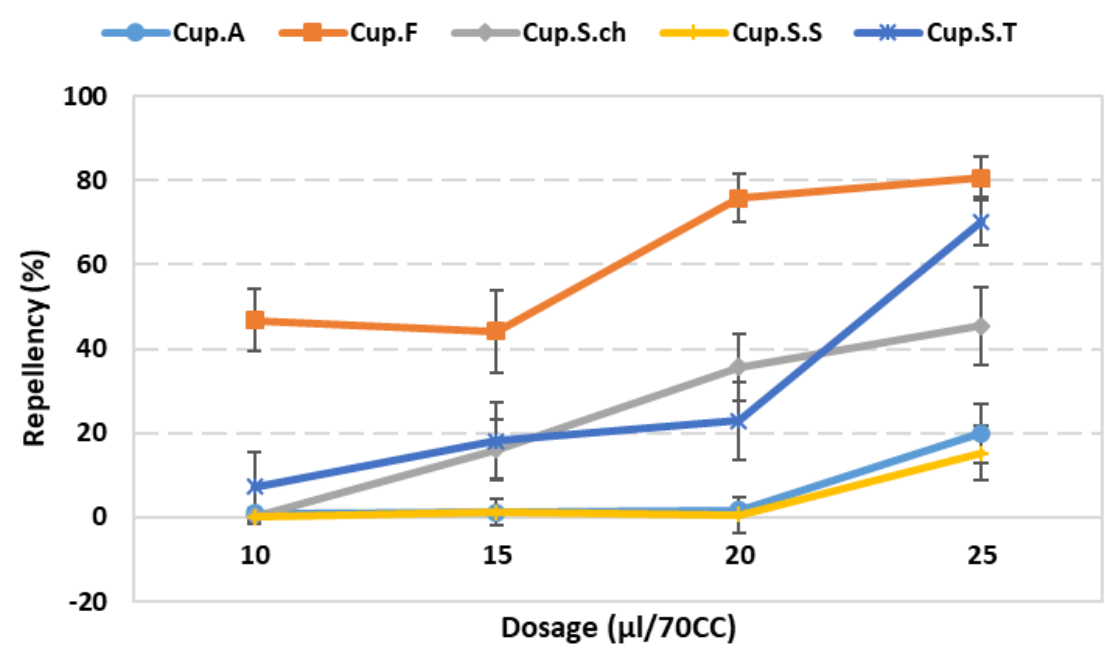

Fig. 2. Percentage repellency of the essential oils from Cupressus in different doses on S. oryzae. Cup.A: C. arizonica, Cup.S.ch: C. sempervirens var. horizontalis (Chalus), Cup.F: C. sempervirens (France), Cup.S.T: C. sempervirens var. horizontalis (Tehran), Cup.S.S: C. sempervirens var stritca.

Table 5. Effects of essential oils on nutritional indices of S. oryzae

\begin{tabular}{lccc}
\hline \multicolumn{1}{c}{ Species } & RGR $(\mathbf{m g} / \mathbf{m g} / \mathbf{d a y})$ & RCR $(\mathbf{m g} / \mathbf{m g} / \mathbf{d a y})$ & ECI $(\%)$ \\
\hline C. sempervirens (Tehran) & $0.662^{\mathrm{c}}$ & $0.711^{\mathrm{b}}$ & $93.122^{\mathrm{b}}$ \\
C. sempervirens (Chalus) & $0.672^{\mathrm{ab}}$ & $0.716^{\mathrm{a}}$ & $94.690^{\mathrm{a}}$ \\
C. arizonica (Tehran) & $0.668^{\mathrm{b}}$ & $0.709^{\mathrm{b}}$ & $93.981^{\mathrm{ab}}$ \\
C. sempervirens (France) & $0.676^{\mathrm{a}}$ & $0.711^{\mathrm{b}}$ & $94.306^{\mathrm{a}}$ \\
\hline
\end{tabular}

RGR: Relative Growth Rate; RCR: Relative Consumption Rate; ECI: Efficiency of Conversion of Ingested food a,b,c Superscript lowercase letters are for significance values. 
Table 6. Effects of different concentrations on nutritional indices of S. oryzae

\begin{tabular}{cccc}
\hline Concentration $(\boldsymbol{\mu l} / \mathbf{3 0} \boldsymbol{\mu l})$ & RGR $(\mathbf{m g} / \mathbf{m g} / \mathbf{d a y})$ & RCR $(\mathbf{m g} / \mathbf{m g} / \mathbf{d a y})$ & ECI $(\%)$ \\
\hline 0 & $0.675 \mathrm{a}$ & $0.713^{\mathrm{a}}$ & $93.033^{\mathrm{b}}$ \\
0.2 & $0.673^{\mathrm{ab}}$ & $0.712^{\mathrm{a}}$ & $93.598^{\mathrm{ab}}$ \\
0.4 & $0.671^{\mathrm{ab}}$ & $0.711^{\mathrm{a}}$ & $94.303^{\mathrm{a}}$ \\
0.8 & $0.666^{\mathrm{bc}}$ & $0.712^{\mathrm{a}}$ & $94.623^{\mathrm{a}}$ \\
1.5 & $0.664^{\mathrm{c}}$ & $0.711^{\mathrm{a}}$ & $94.566^{\mathrm{a}}$ \\
\hline
\end{tabular}

RGR: Relative Growth Rate; RCR: Relative Consumption Rate; ECI: Efficiency of Conversion of Ingested food

a,b,c Superscript lowercase letters are for significance values.

\section{Discussion}

In the experiments, the mortality trend showed that increasing exposure time and concentration of the essential oils increases mortality of insects. The results of this experiment were in accordance with the other results [20]. Researchers examined the insecticidal effect of Salvia sclarea on adult weevil and quadruped beetle insects for 7 consecutive days and found that by increasing exposure time and concentration increased casualties [20].

The $\mathrm{LC}_{50}$ essential oils of $C$. arizonica as bio toxicant for $S$. oryzae after 72 hours $(172.30 \mu \mathrm{l} / \mathrm{L}$ of air) was less than the $\mathrm{LC}_{50}$ of four species, which indicates that it had high toxic property (Table 4). Habibi-Ghozloo et al. [11] examined the essential oils of Pinus eldarica and Cupressus arizonica on 5-day-old moth's insects. Their results showed that Cupressus arizonica with $\mathrm{LC}_{50}$ equivalent of $38.06 \mu \mathrm{l} / \mathrm{L}$ had the lower toxicity than Tehran pine oil with $\mathrm{LC}_{50}$ equivalent of $3.11 \mu \mathrm{l} / \mathrm{L}$. Whereas, Cupressus arizonica had the most toxic effects in our result, this discrepancy can be attributed to the climatic conditions, the insect diversity and the experiment conditions.

According to the results of this study, essential oil of $C$. arizonica causes high respiratory toxicity and the lowest $\mathrm{LC}_{50}$, but in the repellency effect, it causes low repellent effects. This result similar to Bande-Borujeni et al., [1] that these two effects (respiratory toxicity and repellency) do not have a similar trend. The results of BandeBorujeni et al., [1] showed that the respiratory toxicity of Citrus aurantium L. essential oil on the Rhyzopertha dominica Fabricius and Oryzaephilus surinamensis $\mathrm{L}$. $\left(\mathrm{LC}_{50}=0.13\right.$ and $0.11 \mu \mathrm{l} / \mathrm{cm}^{2}$ respectively) was higher than of the Tribolium castaneum (Herbst) $\left(\mathrm{LC}_{50}=1.84 \mu \mathrm{l} /\right.$ $\mathrm{cm}^{2}$ ). While the percentage of $C$. aurantium oil removal for priest $R h$. dominica, T. castaneum and $O$. surinamensis was 48,90 and $84 \%$, respectively, so despite the lower toxicity of the essential oil on the $T$. castaneum, it had high repellent effects on it. The results of another study [15] showed that the essential oils can be used against of $S$. oryzae, $R h$. dominica, T. castaneum, $O$. surinamensis and Callosobruchus chinensis, they found that the $\alpha$ pinene caused $3.47-100 \%$ of the casualties on these insects.

Chemical analysis of the essential oils showed that $\alpha$-pinene was the major components with tha values of 54.98, 34.43, 40.28, 45.48 and $41.42 \%$ in C. sempervirens var. horizentalis (France), C. sempervirens var. horizontalis (Tehran), C. sempervirens var. horizontalis (Chalus), C. sempervirens var. stricta (Chalus) and C. arizonica (Tehran), respectively. The result showed that $C$. sempervirens var. horizentalis (France), C. sempervirens var. stricta and 
C. arizonica (with 54.98, 45.48 and $41.42 \%$ $\alpha$-pinene, respectively) in $428.5 \mu \mathrm{l} / \mathrm{L}$ air dose after 48 hours was $100 \%$ mortality on S. oryzae but the lowest mortality belonged to C. sempervirens var. horizentalis (Tehran) with $34.43 \% \alpha$-pinene.

In fact, by identifying the compounds present in each essential oils can be found that there is a direct relationship between the constituents in each essential oils and its insecticidal properties, and they usually attribute the main effect to the major compound or index.

So far, there has been a great research into the effects of the essential oils repellency against various pests, including the potent repellency effect of the extracts of Asafetida, Lavender and Nerium oleander against Tribolium castaneum $[21,22]$ and a large number of storage pests [23], which confirms the high potential of these natural substances to reduce agricultural pest damage.

The present study also revealed that the essential oils of C. sempervirens (France), $C$. sempervirens (Tehran), C. sempervirens (Chalus) and $C$. arizonica can be used against $S$. oryzae. The results showed that the essential oils repellency depends on their concentration, which was similar with the results of some studies on the effects of essential oils repellency [24, 25]. In the mentioned experimental conditions, $C$. sempervirens (France) essential oils showed the highest and $C$. sempervirens var. stricta essential oils showed the lowest repellency. In this experiment, $C$. arizonica had a repellency effect of $19.89 \%$ which was not significant compared to $C$. sempervirens var. stricta. In the HabibiGhozloo [11] study, C. arizonica had a low repellency effect $(23.52 \%)$, which is corresponds to the present study.

In this study, nutritional indices were used to investigate the anti-nutritional effects of Cupressus species essential oils. The effective factor in reducing insect weight could be related to the effectiveness of the essential oils on insect food, which was measured by the ECI index. In this study, it was found that RGR decreased in all essential oils treatments compared to control. However, the analysis of the anti-nutritional index showed that all the essential oils had antinutritional properties. C. sempervirens (France) and $C$. sempervirens (Chalus) showed the highest ECI in $S$. oryzae with $94.30 \%$ and $94.69 \%$, respectively.

The effect of herbal essential oils on nutrition indices has been studied by different researchers. Reports have shown that the decline in the growth rate of weevil flour by Evodia rutaecarpa is mainly due to insect refusal to eat essential oils (nutritional inhibition) and may not be effective in weight loss due to its ineffective post-feeding ECI toxicity [26].

In addition, the results of research on the insecticidal properties of some Artemisia sieberi Besser and A. scoparia showed that doses of essential oils of these plants, which contain significant amounts of 1 and 8 cineole and camphor which have anti-nutritional properties and prevent insects from eating [27]. In another experiment, it was found that the extract of Ferula asafetida and Artemisia aucheri essential oils on adult weevil flours have anti-nutritional properties [22], which was in agreement with the results of this study.

\section{Conclusion}

Today, due to the growing trend in the use of chemical compounds in pest control and their adverse effects on the environment, researchers have focused on the production and use of safe and low-risk compounds. The use of herbicides and removing herbs is one of the ways in which herbal essential oils have a special place. Due to the toxicity and high repellency effect of 
Cupressus species essential oils on S. oryzae and the low risk of secondary compounds of these herbs for humans and other non-target organisms. Therefore it can suggested that these herbal essential oils should be used as a potential alternative in the form of integrated pest management.

\section{Author contributions}

Project administration: MR. L.; Data analysis: MR. L.; Plant collection: M. A.; Chemical analysis: F. T.; Investigation: M. Kh. and Sh. A.;

\section{References}

1. Bande-Borujeni S, Zandi-Sohani $\mathrm{N}$ and Ramezani L. Chemical composition and insecticidal effects of essential oil from Citrus aurantium L. leaves on three major stored product pests. Plant Protection (Scientific Journal of Agriculture) 2016; 38 (4): 23-32. doi: 10.22055/PPR.2015.11390.

2. Dal Bello GM, Padin S, Lopez Lastra CC and Fabrizio M. Laboratory evaluation of chemicalbiological control of the rice weevil (Sitophilus oryzae L.) in stored grains. J. Stored Prod. Res. 2000; 37(1): 77-84. doi: 10.1016/s0022-474x (00)00009-6.

3. Johnson JA, Vail PV, Soderstrom EL, Curtis CE, Brandl DG, Tebbets JS and Valero KA. Integration of nonchemical, postharvest treatments for control of navel orangeworm (Lepidoptera: Pyralidae) and Indianmeal moth (Lep.: Pyralidae) in walnuts. Journal of Economic Entomology. 1998; 91(6): 1437-1444. doi: 10.1093/jee/91.6.1437.

4. Tunc I, Berger BM, Erler F and Dagli F. Ovicidal activity of essential oils from five plants against two stored-product insects. J. Stored Prod. Res. 2000; 36: 161-168. doi: 10.1016/ S0022-474X(99)00036-3.

5. Rakhshani H. Toxicological principles of pesticides. Farhang publishing. 2003; 376.
Writing original draft: H. Kh. and Sh. A.; Editing: F. KS.

\section{Conflict of interest}

The authors declare that there is no conflict of interest.

\section{Acknowledgement}

The authors would like to thank the Institute of Medicinal plants for the financial support.

6. Mozaffarian V. A Dictionary of Iranian Plant Names: Latin, English, Persian. Seven ${ }^{\text {th }}$ ed., Tehran: Farhang Moaser Publishers; 2013: 169.

7. Mozaffarian V. Trees and Shrubs of Iran. Tehran: Farhang Moaser Publishers; 2005: 1003. 8. Rajendran $S$ and Sriranjini V. Plant products as fumigants for stored-product insect control. $J$. Stored Prod. Res. 2008; 44 (2): 126-135. doi: 10. 1016/j.jspr.2007.08.003.

9. EL-Sheikh TMY, Hassan MI, Moselhy WA, Amer MS and Shehata AZ. Evaluation of the biological activity of some Cupressus semprevirens (Cupressaceae) extracts against the mosquito vector Culex pipiens L (Diptera: Culicidae). Egypt. Acad. J. Biolog. Sci. 2011; 4 (1): 33-48. doi: 10.21608/eajbsa.2011.15170.

10. Amri I, Hanana M, Gargouri S, Jamoussi B and Hamrouni L. Comparative study of two coniferous species (Pinus pinaster Aiton and Cupressus sempervirens L. var. dupreziana [A. Camus] Silba) essential oils: chemical composition and biological activity. Chilean J. Agric. Res. 2013; 73(3): 259-266. doi: 10.4067/S0718-58392013000300008.

11. Habibi Ghozloo F, Moarefi $M$ and Rafiei Karahroodi Z. Fumigant toxicity and repellency effect of essential oils of Pinus eldarica and Cupressus arizonica on adults of flour moth, 
Ephestia kuehniella Zeller. (Lep., Pyralidae). Journal of Entomological Research. 2012; 4 (3): 215-225.

12. Amini S, Ghorbani Nohooji $M$, Khani M, Labbafi MR and Khalighi-Sigaroodi F. Biological activity of some essential oil constituents in four Nepeta L. species against Sitophilus oryzae L. Biodiversitas 2019; 20(2): 338-343. doi: 10.13057/biodiv/d200205.

13. Robertson JL, Russell RM and Savin N. POLO: a user's guide to Probit or Logit analysis. Department of Agriculture, Forest Service, Pacific Southwest Forest; 1980, Vol. 38.

14. McDonald LL, Guy RH and Speirs RD. Preliminary evaluation of new candidate materials as toxicants, repellents, and attractants against stored-product insects. US Agricultural Research Service; 1970.

15. Ogendo J, Deng A, Kostyukovsky M, Ravid U, Matasyoh J, Omolo E, Kariuki S, Bett P and Kamau E. Fumigant toxicity of five essential oil constituents against major stored-product insect pests of food grains. In: Second RUFORUM Biennial Regional Conference on" Building capacity for food security in Africa", Entebbe, Uganda, 20-24 September 2010. RUFORUM; 2010: 325-332.

16. Xie YS, Bondaryk RP and Fields PG. A rapid and simple flour disk bioassay for testing natural substances active against stored-product insects. Can. Entomol. 1996; 128: 865-875. doi: 10.4039/Ent128865-5.

17. Huang Y, Ho SH, Lee HC and Yap YL. Insecticidal properties of eugenol, isoeugenol and methyleugenol and their effects on nutrition of Sitophilus zeamais Motsch. (Coleoptera: Curculionidae) and Tribolium castaneum (Herbst) (Coleoptera: Tenebrionidae). J. Stored Prod. Res. 2002; 38: 403-412. doi: 10.1016/ S0022-474X(01)00042-X.
18. Adams RP. Identification of essential oil components by gas chromatography/mass spectrometry. Allured publishing corporation Carol Stream, IL; 2007, Vol. 456.

19. Johnston C. The Wiley/NBS Registry of Mass Spectral Data, Volumes 1-7 (McLafferty, Fred W.; Stauffer, Douglas B.). J. Chem. Educ. 1989, 66, 10, A256. doi.org/10.1021/ ed066pA256.3.

20. Nabavi B, Talebi Jahromi K, Goldansaz SH, Khalighi-Sigaroodi F, Hoseini Naveh $\mathrm{V}$ and Esmailzade NS. Insecticidal effect of clary sage (Salvia sclarea) essential oil against Callosobruchus maculatus (Col: Bruchidae) and Tribolium confusum (Col: Tenebrionodae). J. Med. Plants 2012; 10 (39 and S7): 25-33.

21. Nazemi Rafih $\mathbf{J}$ and Moharramipour $\mathrm{S}$. Repellency of Nerium oleander L., Lavandula officinalis L. and Ferula assafoetida L. extracts on Tribolium castaneum (Herbst). Iranian Journal of Medicinal and Aromatic Plants 2008; 23(4): 443-452.

22. Moharramipour S, Nazemi Rafieh J, Morovati M, Talebi AA and Fathipour Y. Effectiveness of extracts of Nerium oleander, Lavandula officinalis and Ferula assafoetida on nutritional indices of Tribolium castaneum adults. JESI 2003; 23(1): 69-89.

23. Nerio LS, Olivero-Verbel $\mathrm{J}$ and Stashenko EE. Repellent activity of essential oils from seven aromatic plants grown in Colombia against Sitophilus zeamais Motschulsky. (Coleoptera). J. Stored Prod. Res. 2009; 45(3): 212-214. doi: 10.1016/j.jspr.2009.01.002.

24. Hariri Moghadam F, Moharramipour S and Sefidkon F. Repellent activity and persistence of essential oil from Eucalyptus salmonophloia F. Muell and Eucalyptus kingsmillii (Mauden) Maiden \& Blakely on two spotted spider mite, Tetranychus urticae Koch. Iranian Journal of 
Medicinal and Aromatic Plants 2012; 27 (3): 375-383. doi: 10.22092/ijmapr.2011.6379.

25. Misni N, Sulaiman S and Othman H. The repellent activity of Piper aduncum Linn (Family: Piperaceae) essential oil against Aedes aegypti using human volunteers. J. Trop. Med. Parasitol. 2008; 31: 63-69.

26. Liu ZL and Ho SH. Bioactivity of the essential oil extracted from Evodia rutaecarpa Hook f. et Thomas against the grain storage insects, Sitophilus zeamais Motsch. and Tribolium castaneum (Herbst). J. Stored Prod. Res. 1999; 35(4): 317-328. doi: 10.1016/S0022474X(99)00015-6.
27. Negahban $M$ and Moharramipour $S$. Efficiency of Artemisia sieberi and Artemisia scoparia essential oils on nutritional indices of Tribolium castaneum (Col: Tenebrionidae). Iranian Journal of Medicinal and Aromatic Plants 2007; 23(1): 13-22.

How to cite this article: Labbafi MR, Ahvazi M, Khalighi-Sigaroodi F, Khalaj H, Ahmadian S, Tajabadi F, Khani M, Amini Sh. Essential oil bioactivity evaluation of the different populations of Cupressus against adult rice weevil (Sitophilus oryzae L.). Journal of Medicinal Plants 2021; 20(77): 79-92.

doi: 10.29252/jmp.20.77.79 


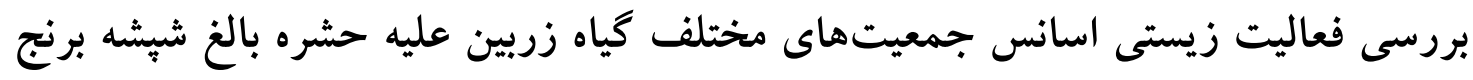

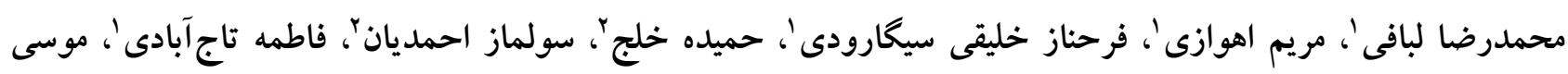

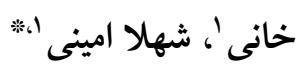

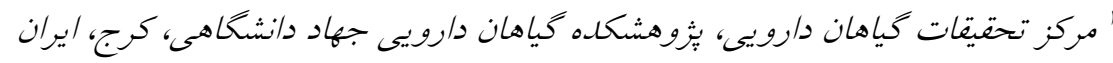

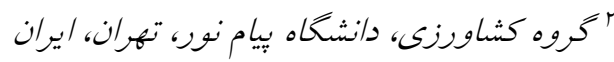

\begin{tabular}{|c|c|}
\hline جكيده & اطلاعات مقاله \\
\hline 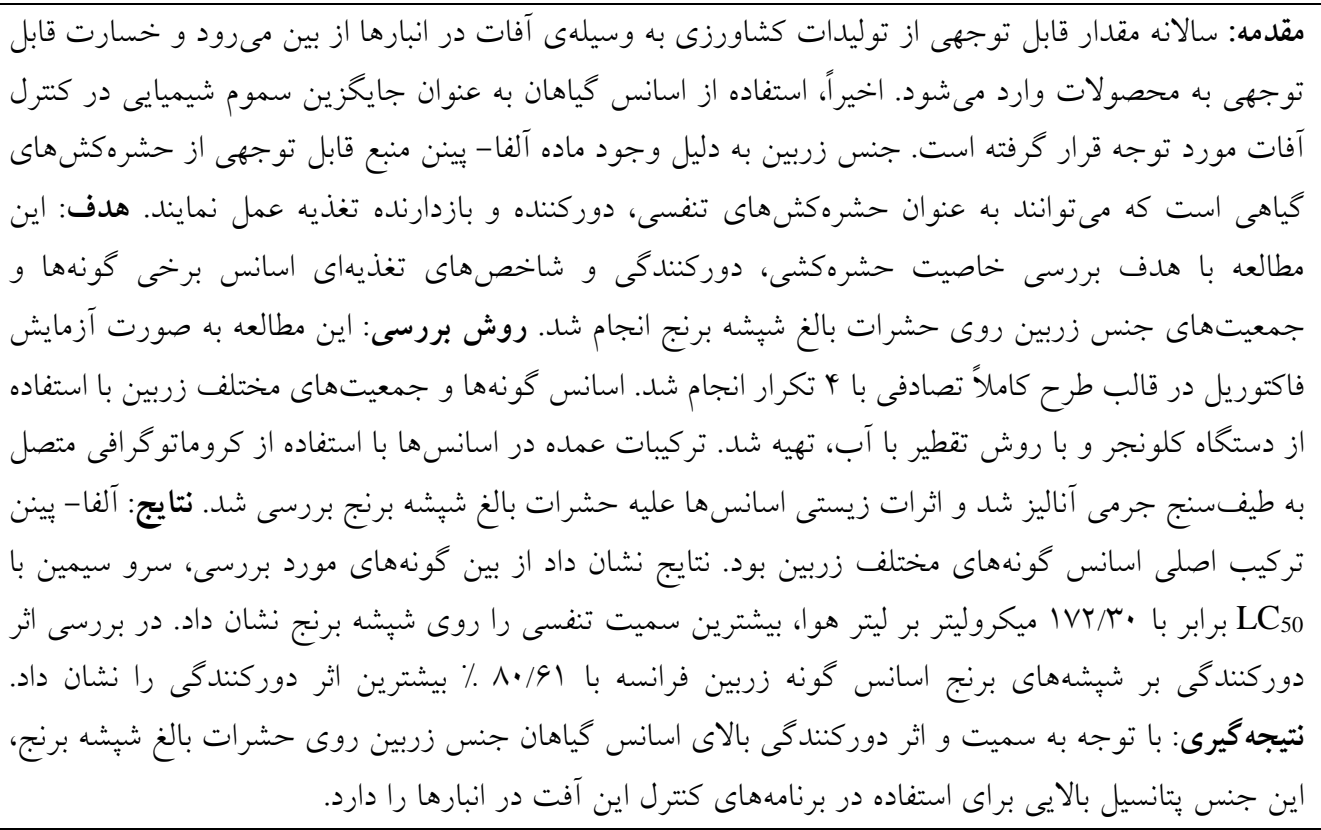 & 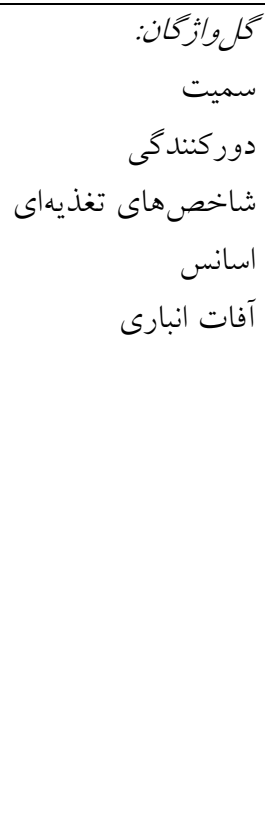 \\
\hline
\end{tabular}

doi: $10.29252 /$ jmp.20.77.79

(C) 2020. Open access. This article is distributed under the terms of the Creative Commons Attribution-NonCommercial 4.0 International License (https://creativecommons.org/licenses/by-nc/4.0/) 